\title{
Impacts of the Replacement of Native Woodland with Exotic Pine Plantations on Leaf-Litter Invertebrate Assemblages: A Test of a Novel Framework
}

\author{
Brad R. Murray, Andrew C. Baker, and Tessa C. Robson \\ Plant Functional Biology and Climate Change Cluster, Department of Environmental Sciences, University of Technology Sydney, \\ P.O. Box 123, Broadway, NSW 2007, Australia \\ Correspondence should be addressed to Brad R. Murray, brad.murray@uts.edu.au
}

Received 2 September 2009; Accepted 2 November 2009

Recommended by L. M. Chu

\begin{abstract}
We present an empirical comparison of invertebrate community structure between areas of undisturbed native eucalypt woodland and areas that have been cleared and replaced with plantations of exotic radiata pine (Pinus radiata). Implementation of a novel conceptual framework revealed that both insect (in autumn) and arachnid (in winter) assemblages demonstrated inhibition in response to the pine plantations. Species richness declines occurred in several taxonomic Orders (e.g., Hymenoptera, Blattodea, Acari) without compensated increases in other Orders in plantations. This was, however, a seasonal response, with shifts between inhibition and equivalency observed in both insects and arachnids across autumn and winter sampling periods. Equivalency responses were characterized by relatively similar levels of species richness in plantation and native habitats for several Orders (e.g., Coleoptera, Collembola, Psocoptera, Araneae). We propose testable hypotheses for the observed seasonal shifts between inhibition and equivalency that focus on diminished resource availability and the damp, moist conditions found in the plantations. Given the compelling evidence for seasonal shifts between categories, we recommend that seasonal patterns should be considered a critical component of further assemblage-level investigations of this novel framework for invasion ecology.
\end{abstract}

Copyright ( $) 2009$ Brad R. Murray et al. This is an open access article distributed under the Creative Commons Attribution License, which permits unrestricted use, distribution, and reproduction in any medium, provided the original work is properly cited.

\section{Introduction}

The replacement of native habitat-providing plant species with exotic species is a global phenomenon that can lead to a range of ecological impacts on native flora and fauna. Such a situation can arise, for instance, when native woodland vegetation is cleared and replaced with exotic plantation species [1]. For instance, in the Southern Hemisphere, radiata pine (Pinus radiata D. Don) is a widely planted exotic conifer that now occupies over four million hectares of plantation outside its natural range $[2,3]$. Recently, a novel conceptual framework was established to identify the ecological responses of species assemblages to the replacement of native vegetation with exotic species [4]. There were two motivations for developing such an assemblagelevel framework. First, the impacts of exotic species on native species are incredibly varied, to the extent that some species flourish, some remain unaffected and others suffer badly $[5,6]$. This suite of potential responses makes it difficult to predict how individual species will respond to new habitat provided by exotic species. Second, we are far from understanding the full range of ecological impacts brought about by replacing native habitat-providing species with exotic species [7].

The novelty of the Sax et al. [4] framework is that it allows concurrent and direct comparison of quantitative measures of community structure (e.g., species richness) for multiple taxonomic components of assemblages between areas of native vegetation and areas where exotic species are the new habitat providers. The advantage of such a scheme is that it does not try to predict how each individual native taxon responds to new habitat conditions provided by exotic species, but rather, it assesses the overall response at the assemblage level (e.g., [8]). In this context, the Sax et al. 
[4] framework identifies four categorical responses of assemblages to exotic habitat-providing species: (1) equivalency, where the measured characteristic of the assemblage (e.g., species richness of multiple taxonomic Orders in a larger clade) is relatively similar between habitats for each Order; (2) compensation, where a decline in species richness of one Order is compensated for by an increase in species richness of another Order in the exotic habitat; (3) inhibition, where a decline in species richness in the exotic habitat is observed in one or more Orders without increases in other Orders; and (4) facilitation, where an increase in species richness in the exotic habitat is observed in one or more Orders without decreases in other Orders.

While Sax et al. [4] gathered data from previously published studies to explore the utility of their framework [8-14], there have been no studies explicitly designed to test the framework since its inception. Here, we provide the first targeted empirical test of the Sax et al. [4] framework. We compare species assemblages of two major invertebrate clades, insects and arachnids, between native woodland and areas that have been cleared and replaced with plantations of exotic radiata pine (Pinus radiata). Our study focuses on a key measure of biodiversity, species richness [15], and reports how species richness differs between native woodland and pine plantations across insect and arachnid taxonomic Orders.

\section{Methods}

The study was conducted at three pine plantation sites (exotic habitat) and three woodland sites (native habitat) in the Jenolan Caves Karst Conservation Reserve $\left(33^{\circ} 49^{\prime} \mathrm{S}\right.$, $150^{\circ} 02^{\prime} \mathrm{E}$ ), located c. $180 \mathrm{~km}$ west of Sydney in southeastern Australia (see [16] for a description of the study area). Native woodland is dominated by Eucalyptus species with an understorey characterised by herbs, grasses, and the occasional larger shrub species (e.g., Exocarpos strictus and Leucopogon lanceolatus). Pine plantations are mature (c. 20 years old) with a closed canopy. All sites were located $70 \mathrm{~m}$ away from habitat edges to discount possible edge effects [17]. Sites were selected based on similarity with respect to underlying soil type, slope, and drainage. Sampling of leaf-litter insects and arachnids was conducted twice during autumn and winter within $9 \mathrm{~m} \times 3 \mathrm{~m}$ sampling quadrats at each site. Three $2 \mathrm{~L}$ samples of leaf litter (spaced $>2 \mathrm{~m}$ apart) were randomly selected within each quadrat, bagged, and transported to the laboratory for extraction of insects and arachnids. Extraction was undertaken within 12 hours of sampling using Burlese funnels. Burlese funnels were constructed by cutting the bottoms off $2 \mathrm{~L}$ soda bottles, inserting gauze mesh to contain the litter sample, and attaching a specimen jar half-filled with preservative (70\% ethanol $/ 2 \%$ glycerol) at the bottom of the bottle. Funnels were housed in one of two custom-built, portable invertebrate-proof boxes. A $75 \mathrm{~W}$ light bulb was housed in the lid above each funnel to provide the heat needed to drive invertebrates out of the litter, through the gauze and into specimen jars. Extraction was undertaken for a period of 3 days. Following extraction, insects and arachnids were identified to Order [18] and to morphospecies using morphological features (hereafter, we refer to morphospecies as species for brevity).

In accordance with the framework described in Sax et al. [4], we produced a series of graphs to allow visual inspection of the overall responses of insect and arachnid communities to the replacement of native habitat with exotic pine plantations. We compared species richness [15] within insect and arachnid Orders between native and exotic habitats. Values of species richness within each Order in exotic pine plantation sites ( $y$-axis) were plotted against values within the same Orders in native eucalypt woodland sites ( $x$-axis), separately for the autumn and winter sampling periods. Insect and arachnid assemblages were plotted on separate graphs. Species richness within each Order was determined as the average across the three pine plantation sites (exotic habitat) and across the three eucalypt woodland sites (native habitat). Each point on a graph represented average species richness of a taxonomic Order in nonnative habitat versus native habitat with standard errors provided along each axis. A 1 : 1 line was positioned on each graph in order to determine whether each point fell above the line (i.e., higher richness in the nonnative sites compared with native sites) or below the line (i.e., lower richness in the nonnative sites compared with native sites). For equivalency, all points would not deviate dramatically from the 1 : 1 line. A compensation response would be revealed by one or more points deviating substantially above the 1 : 1 line and one or more points deviating substantially below the 1 : 1 line. For inhibition, all or most points would be found well below the 1 : 1 line. In the case of facilitation, all or most points would be found well above the 1 : 1 line. In the present study, to distinguish between the overall responses of insect and arachnid communities to the replacement of native habitat with exotic pine plantations, we used the visual analysis [4] described above in combination with the following procedure. If the greater majority of points fell above (facilitation) or below (inhibition) the line of equivalency and none of the standard error bars overlapped this line, then categorization into these response types was considered robust.

Nested two-factor analysis of variance (ANOVA) was employed in JMP IN v 4.0 to compare the aggregate richness of all insect species between site condition (fixed factor: pine plantation or native woodland) and among the three replicate sites (random factor nested within condition). The same test was used to compare the aggregate richness of all arachnids. Our analyses revealed no significant effects of site nested within condition, thus we present only the statistical results of tests between site conditions. These tests were used to confirm the nature of the response of assemblages, given that aggregate species richness found in exotic habitats will not be significantly different to aggregate species richness in native habitat in cases of equivalency or compensation, significantly lower in the case of an inhibition response and significantly higher in the case of a facilitation response [4]. 


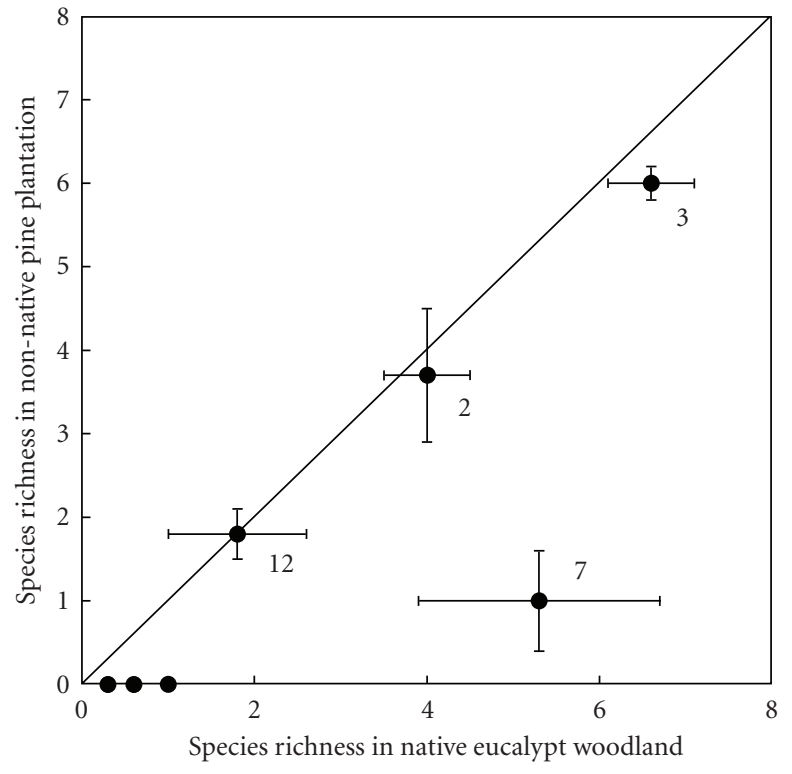

(a) Inhibition insects in autumn

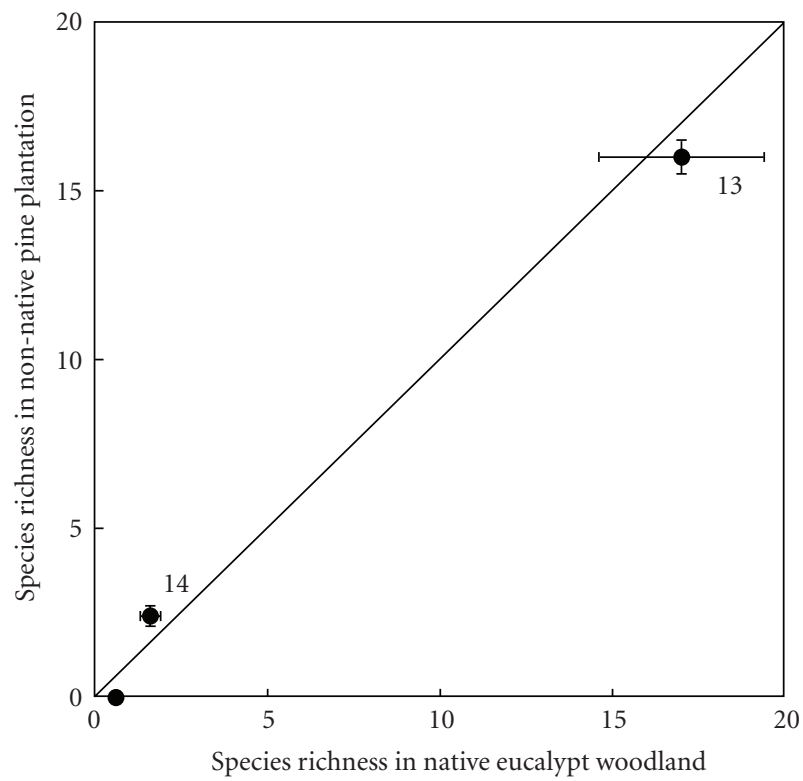

(c) Equivalency arachnids in autumn

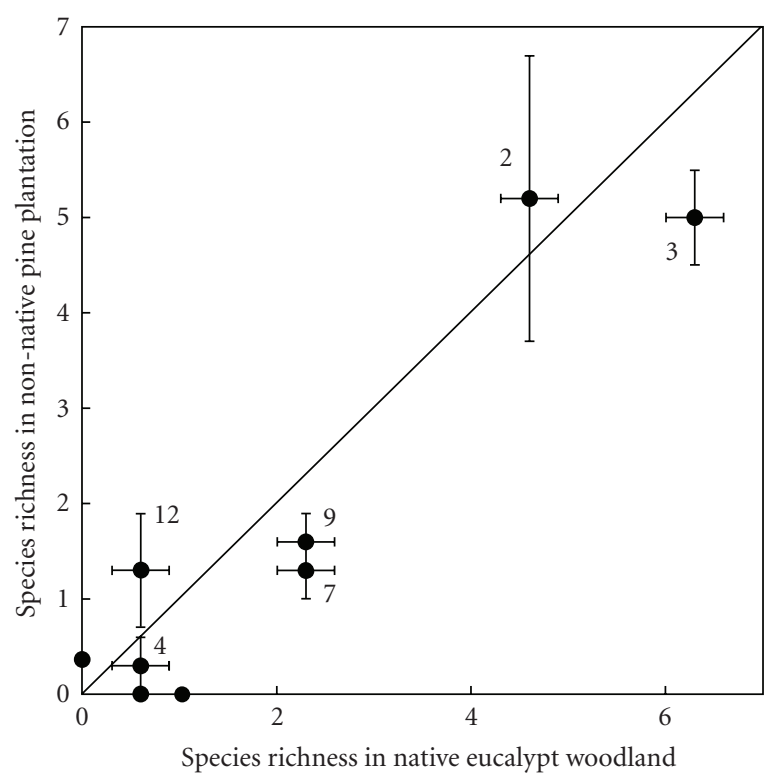

(b) Equivalency insects in winter

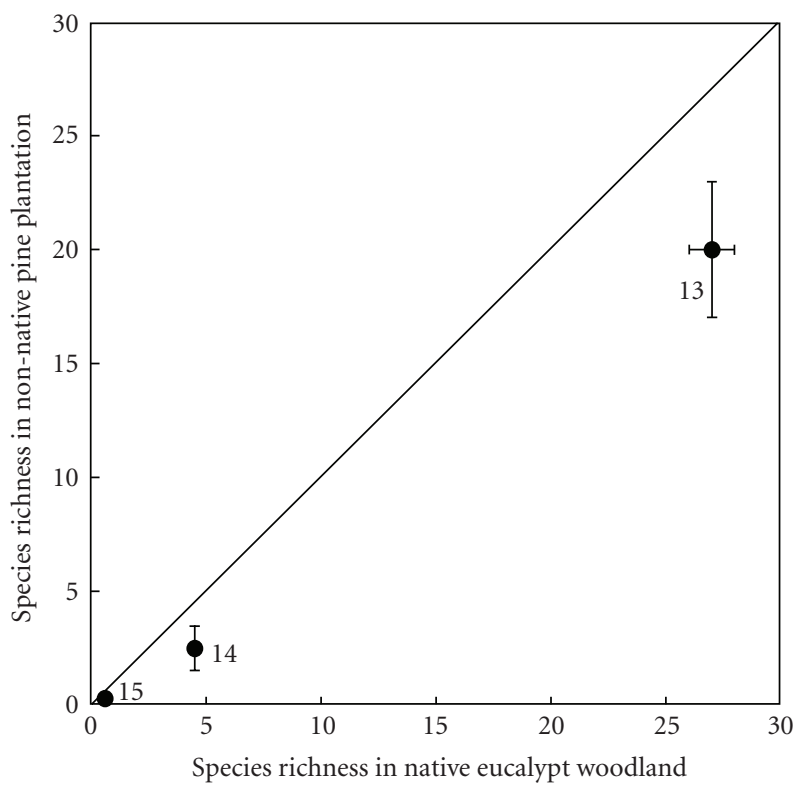

(d) Inhibition arachnids in winter

FIGURE 1: Values of species richness $( \pm$ SE) for multiple taxonomic components of insect and arachnid assemblages in native eucalypt woodland and exotic pine plantations. (a) insects in autumn, (b) insects in winter, (c) arachnids in autumn, (d) arachnids in winter. Orders numbered on graphs are Blattodea ${ }^{1}$, Coleoptera $^{2}$, Collembola $^{3}$, Diptera ${ }^{4}$, Embioptera $^{5}$, Hemiptera $^{6}$, Hymenoptera $^{7}$, Isopoda $^{8}$, Lepidoptera $^{9}$, Neuroptera $^{10}$, Orthoptera $^{11}$, Psocoptera ${ }^{12}$, Acari ${ }^{13}$, Araneae ${ }^{14}$, and Pseudoscorpiones ${ }^{15}$. In (a), Orders 1, 4, 6, 9, 10, and 11 are absent from pine plantation sites (zero values on $y$-axis) but represented in eucalypt woodland sites by a small number of species. In (b), Orders 1 and 6 are absent from pine plantation sites but represented in eucalypt woodland sites by a small number of species. Note that in (b), Orders 5 and 8 are absent from eucalypt woodland sites but represented by a small number of species in pine plantation sites. In (c), Order 15 is absent from pine plantation sites but represented in eucalypt woodland sites by a small number of species.

\section{Results}

An inhibition response was detected among insect assemblages in pine plantations in autumn. There was a substantial decline in species richness in the Order Hymenoptera in plantations compared with native woodland (Figure 1(a)).
A comparison of the aggregate richness of all insect species further demonstrated an inhibition response with significantly more insect species found overall in native woodland compared with plantations $\left(F_{1,4}=20.90, P<.001\right)$. In contrast to the inhibition response observed in autumn, an equivalency response was detected among insect assemblages 
in winter with no insect Orders deviating markedly from the 1 : 1 line (Figure 1(b)). Consistent with this, there was no significant difference in the aggregate richness of insect species between plantations and woodland in winter $\left(F_{1,4}=0.57, P=.49\right)$. Notably, several insect Orders (Blattodea, Hemiptera, Neuroptera, Orthoptera) were not found in plantations in either autumn or winter.

An inhibition response was detected among arachnid assemblages in pine plantations in winter, despite the presence of only three data-points (Figure 1(d)). This inhibition response is remarkably similar to the inhibition response detected by Sax et al. [4] in parasites of fish in Mexico [14]. Most notably, there were fewer Acarine species in plantations compared with native woodland (Figure 1(d)). In addition, the aggregate richness of all arachnid species was significantly lower in plantations compared with woodland $\left(F_{1,4}=\right.$ 16.92, $P=.01)$. In contrast to the inhibition response observed in winter, an equivalency response was detected among arachnid assemblages in autumn (Figure 1(c)). In keeping with an equivalency response, there was no significant difference in the aggregate richness of arachnid species between pine plantations and native woodland in autumn $\left(F_{1,4}=0.34, P=.59\right)$.

\section{Discussion}

Both insect and arachnid assemblages demonstrated seasonal shifts between inhibition and equivalency in response to new habitat provided by exotic pine plantations. Insect assemblages switched from inhibition in autumn to equivalency in winter. This switch was generated primarily by lower richness of Hymenopteran species in plantation sites compared with woodland sites in autumn. In winter, there was an equivalent (and low) species richness of Hymenoptera in both plantations and woodland. Arachnid assemblages shifted from equivalency in autumn to inhibition in winter. The arachnid switch was generated by species richness in Acari dropping from equivalent plantation-woodland levels in autumn to lower levels in the plantations in winter. Interestingly, despite the seasonal shifts observed between equivalency and inhibition with respect to species richness, recent work has shown that the composition of invertebrate assemblages is consistently and significantly different between seasons and thus does not appear to shift in tandem with the metric of species richness used in the present study [19]. In other words, although in some cases there may be no changes in species richness detected across a range of invertebrate taxa between plantation and non-plantation sites in a given season (i.e., equivalency in insects in winter), the actual composition of the invertebrate assemblages still differs [20]. Overall, however, the compelling evidence for shifts between categories of the framework that we detected in the present study suggests that seasonal patterns should be considered a critical component of further assemblage level investigations of the Sax et al. [4] framework. Furthermore, given that our study did not set out to examine how different metrics of biodiversity relate to each other across seasons, we suggest that longer-term studies encompassing several years of seasonal change should set out to use and compare measures such as species richness, abundance, diversity, and composition, and perhaps also sophisticated phylogenetic measures (e.g., [21]).

The comparatively high species richness of Hymenopteran taxa in native woodland in autumn is possibly a result of a diverse range of native plants flowering in this native habitat during autumn. A number of species from the families Asteraceae, Orchidaceae, Plantaginaceae, and Ranunculaceae, which are not present in plantations, are known to flower profusely in autumn (Baker, pers. obs.). A robust test of the idea that a higher incidence of floral resources, key food sources for Hymenopteran taxa, could lead to a plantation-woodland difference in species richness in autumn requires that future studies should concurrently examine patterns of phenology in the native woodland in relation to species richness of Hymenopteran taxa. Such a study would also be able to explore the overall shift from inhibition to equivalency in insects. Here, the prediction to be tested is that equivalently low species richness of Hymenoptera in both plantations and native woodland in winter is linked to low levels of flowering in native woodland during winter.

The low species richness within Acari in winter in the plantations was most likely due to the overabundance of a small number of Acari species [20]. It is possible that these few, overabundant taxa may have outcompeted several other Acarine species, thus reducing overall species richness in the plantation. This hypothesis remains to be experimentally tested, but given that mites thrive under cool, dark, and moist conditions [18] and that rainfall in the area was exceptionally and unusually higher in winter than in autumn [22], a possible outcome of further investigations involving manipulative experiments might be the identification of a group of highly competitive Acarine taxa that flourish under very wet conditions. However, there also remains the possibility that some Acarine taxa are excluded under these conditions not as a result of competition, but rather due to a lack of appropriate resources (or perhaps some other niche limitation). The increase in numbers of individuals within particular Acarine species would then simply be due to density compensation.

Our plantation study sites are effectively monocultures consisting of adult pine plants, pine debris, and a thick mat of decaying pine needles with virtually no understorey vegetation [20]. In contrast, native woodland sites contain a more diverse and rich suite of understorey plant species [16, 17]. We suggest that this stark difference in habitat heterogeneity is primarily responsible for the complete absence of species from several insect Orders in plantations (see [19]). Radiata pine plants can arguably be considered as introduced ecosystem engineers (sensu $[23,24]$ ). Such engineers that decrease habitat complexity and heterogeneity tend to cause species richness of resident species to decrease [25]. The absences of species from the Orders Blattodea, Hemiptera, Neuroptera, and Orthoptera in the plantations in both autumn and winter are most likely due to the comparatively lower habitat heterogeneity seen in plantations. Insect Orders absent from plantations tended to be those that rely on 
a diverse range of angiosperm plants for food. For example, Orthopteran species are primarily phytophagous, relying on the foliage of higher plants, while the characteristic features of Hemipteran taxa are sucking mouthparts for extracting liquids from plants [18].

The heterogeneous understorey in the native woodland sites not only provides a greater array of angiosperm food sources for a range of different invertebrate fauna, but also provides a diverse leaf litter, bark and rotting logs as habitat [26]. Indeed, vertebrate taxa that require the nectar and fruit of angiosperms (e.g., hollow-nesting birds and arboreal marsupials) have similarly been recorded in reduced numbers in plantations [27-29]. Many invertebrate taxa are also much less mobile than vertebrates and have developed intimate links with particular components of native vegetation for their survival [30]. Standish [31], for example, found that altered microclimatic conditions and food resources brought about by the invasive herbaceous weed Tradescantia fluminensis resulted in reduction in suitable habitat for invertebrates which led to dramatic changes in invertebrate communities. Similarly, Lindsay and French [32] found that the dense understorey formed by the invasive weed Chrysanthemoides monilifera (Bitou bush) altered invertebrate communities through changed microclimates and resource availability.

Interestingly, several insect taxa (Coleoptera, Collembola, Psocoptera) displayed equivalent levels of species richness in plantation sites and woodland sites in both seasons. Among arachnids, species richness in Araneae and Pseudoscorpiones also remained fairly consistent between plantations and woodland in both seasons. Such patterns suggest that these taxa are fairly resilient to the changes brought about the replacement of native woodland with exotic pine plantations. Previous studies targeting specific invertebrate taxa have also identified taxa that seem robust to the presence of plantations (e.g., [33-35]). Neumann [36] and Gunther and New [35] reported that radiata pine plantations can harbor a substantial suite of beetles and identified a diverse range of Coleopteran families and morphospecies within plantations.

We found no evidence in either the insect or arachnid assemblages of facilitation or compensation with respect to species richness within invertebrate Orders. Data gathered from previously published studies to explore the framework [4] revealed that equivalency in species richness was the most common response of assemblages (4 out of 6 datasets) to the replacement of native habitat-providing species with nonnatives (see also [8]). One dataset revealed inhibition for parasites of fish in Mexico [14], another revealed facilitation for invertebrate taxa of mudflat habitats in Australia [13]. The ubiquity of an equivalency response, observed here and in Sax et al. [4], across a range of taxa and a range of nonnative habitat-providing species is consistent with the findings of Brown et al. [37] who found that species richness within many assemblages remains unaltered despite large changes in species composition. Nevertheless, our study demonstrated seasonal shifts between equivalency and inhibition across multiple Orders in both insects and arachnids in response to large changes in species composition. Understanding and experimentally testing the potential mechanisms involved in generating these responses and shifts should be key goals of research exploring the range of impacts of introduced ecosystem engineers $[25,38,39]$.

\section{Acknowledgments}

The authors thank The Jenolan Caves Trust, Ian Robson, Alan Wright, Ian Baker, VisyPak Beverages, and Nathan Muir. They are grateful to an anonymous reviewer who provided helpful and insightful comments on an earlier version of the paper.

\section{References}

[1] D. M. Richardson and S. I. Higgins, "Pines as invaders in the southern hemisphere," in Ecology and Biogeography of Pinus, D. M. Richardson, Ed., pp. 450-473, Cambridge University Press, Cambridge, UK, 1998.

[2] D. M. Richardson, P. A. Williams, and R. J. Hobbs, "Pine invasions in the Southern Hemisphere: determinants of spread and invadability," Journal of Biogeography, vol. 21, no. 5, pp. 511-527, 1994.

[3] D. M. Richardson, Ecology and Biogeography of Pinus, Cambridge University Press, Cambridge, UK, 1998.

[4] D. F. Sax, B. P. Kinlan, and K. F. Smith, "A conceptual framework for comparing species assemblages in native and exotic habitats," Oikos, vol. 108, no. 3, pp. 457-464, 2005.

[5] J. L. Lockwood, M. F. Hoopes, and M. P. Marchetti, Invasion Ecology, Blackwell, Oxford, UK, 2007.

[6] B. R. Murray, C. R. Dickman, T. Robson, et al., "Effects of exotic plants in native vegetation on species richness and abundance of birds and mammals," in Pest or Guest: The Zoology of Overabundance, D. Lunney, P. Eby, P. Hutchings, and S. Burgin, Eds., pp. 216-221, Royal Zoological Society of NSW, Mosman, Australia, 2007.

[7] J. M. Levine, M. Vilà, C. M. D’Antonio, J. S. Dukes, K. Grigulis, and S. Lavorel, "Mechanisms underlying the impacts of exotic plant invasions," Proceedings of the Royal Society B, vol. 270, no. 1517, pp. 775-781, 2003.

[8] D. F. Sax, "Equal diversity in disparate species assemblages: a comparison of native and exotic woodlands in California," Global Ecology and Biogeography, vol. 11, no. 1, pp. 49-57, 2002.

[9] L. M. Ellis, "Bird use of saltcedar and cottonwood vegetation in the Middle Rio Grande Valley of New Mexico, USA," Journal of Arid Environments, vol. 30, no. 3, pp. 339-349, 1995.

[10] L. M. Ellis, C. S. Crawford, and M. C. Molles Jr., "Rodent communities in native and exotic riparian vegetation in the Middle Rio Grande Valley of central New Mexico," Southwestern Naturalist, vol. 42, no. 1, pp. 13-19, 1997.

[11] R. M. Viejo, "Mobile epifauna inhabiting the invasive Sargassum muticum and two local seaweeds in Northern Spain," Aquatic Botany, vol. 64, no. 2, pp. 131-149, 1999.

[12] L. M. Ellis, M. C. Molles Jr., C. S. Crawford, and F. Heinzelmann, "Surface-active arthropod communities in native and exotic riparian vegetation in the Middle Rio Grande Valley, New Mexico," Southwestern Naturalist, vol. 45, no. 4, pp. 456471,2000 
[13] P. Hedge and L. K. Kriwoken, "Evidence for effects of Spartina anglica invasion on benthic macrofauna in Little Swanport estuary, Tasmania," Austral Ecology, vol. 25, no. 2, pp. 150-159, 2000.

[14] G. Pérez-Ponce de León, L. García-Prieto, V. León-Règagnon, and A. Choudhury, "Helminth communities of native and introduced fishes in Lake Pátzcuaro, Michoacan, Mexico," Journal of Fish Biology, vol. 57, no. 2, pp. 303-325, 2000.

[15] K. J. Gaston and J. I. Spicer, Biodiversity: An Introduction, Blackwell Science, Oxford, UK, 2nd edition, 2004.

[16] A. C. Baker, G. C. Hose, and B. R. Murray, "Vegetation responses to Pinus radiata (D. Don) invasion: a multivariate analysis using principal response curves," Proceedings of the Linnean Society of New South Wales, vol. 127, no. 1, pp. 191197, 2006.

[17] A. C. Baker, B. R. Murray, and G. C. Hose, "Relating pine-litter intrusion to plant-community structure in native eucalypt woodland adjacent to Pinus radiata (Pinaceae) plantations," Australian Journal of Botany, vol. 55, no. 5, pp. 521-532, 2007.

[18] CSIRO, The Insects of Australia, Melbourne University Press, Melbourne, Australia, 2nd edition, 1991.

[19] T. C. Robson, A. C. Baker, and B. R. Murray, "Differences in leaf-litter invertebrate assemblages between radiata pine plantations and neighbouring native eucalypt woodland," Austral Ecology, vol. 34, no. 4, pp. 368-376, 2009.

[20] T. C. Robson, The effects of Pine (Pinus radiata D. Don) plantations on leaf-litter invertebrates, unpublished thesis, University of Technology Sydney, Sydney, Australia, 2007.

[21] M. W. Cadotte, M. A. Hamilton, and B. R. Murray, "Phylogenetic relatedness and plant invader success across two spatial scales," Diversity and Distributions, vol. 15, no. 3, pp. 481-488, 2009.

[22] BoM, Commonwealth Bureau of Meteorology, Australia. Meteorology on the net, 2008, http://www.bom.gov.au/.

[23] C. G. Jones, J. H. Lawton, and M. Shachak, "Organisms as ecosystem engineers," Oikos, vol. 69, no. 3, pp. 373-386, 1994.

[24] C. G. Jones, J. H. Lawron, and M. Shachak, "Positive and negative effects of organisms as physical ecosystem engineers," Ecology, vol. 78, no. 7, pp. 1946-1957, 1997.

[25] J. A. Crooks, "Characterizing ecosystem-level consequences of biological invasions: the role of ecosystem engineers," Oikos, vol. 97, no. 2, pp. 153-166, 2002.

[26] K. M. Parris and D. B. Lindenmayer, "Evidence that creation of a Pinus radiata plantation in South-Eastern Australia has reduced habitat for frogs," Acta Oecologica, vol. 25, no. 1-2, pp. 93-101, 2004.

[27] A. J. Armstrong and H. J. van Hensbergen, "Impacts of afforestation with pines on assemblages of native biota in South Africa," Suid-Afrikaanse Bosboutydskrif, vol. 175, pp. 35-42, 1996.

[28] D. B. Lindenmayer, R. B. Cunningham, C. F. Donnelly, H. Nix, and B. D. Lindenmayer, "Effects of forest fragmentation on bird assemblages in a novel landscape context," Ecological Monographs, vol. 72, no. 1, pp. 1-18, 2002.

[29] D. B. Lindenmayer and R. J. Hobbs, "Fauna conservation in Australian plantation forests: a review," Biological Conservation, vol. 119, no. 2, pp. 151-168, 2004.

[30] L. D. Ahern and A. L. Yen, "A comparison of the invertebrate fauna under Eucalyptus and Pinus forests in the Otway ranges," Proceedings of the Royal Society of Victoria, vol. 89, pp. 127136, 1977.
[31] R. J. Standish, "Impact of an invasive clonal herb on epigaeic invertebrates in forest remnants in New Zealand," Biological Conservation, vol. 116, no. 1, pp. 49-58, 2004.

[32] E. A. Lindsay and K. French, "The impact of the weed Chrysanthemoides monilifera ssp. rotundata on coastal leaf litter invertebrates," Biological Invasions, vol. 8, no. 2, pp. 177192, 2006.

[33] F. G. Neumann, "Insect populations in eucalypt and pine forests in North-Eastern Victoria," Australian Forest Research, vol. 8, pp. 13-24, 1978.

[34] K. J. Bonham, R. Mesibov, and R. Bashford, "Diversity and abundance of some ground-dwelling invertebrates in plantation vs. native forests in Tasmania, Australia," Forest Ecology and Management, vol. 158, no. 1-3, pp. 237-247, 2002.

[35] M. J. Gunther and T. R. New, "Exotic pine plantations in Victoria, Australia: a threat to epigaeic beetle (Coleoptera) assemblages?" Journal of Insect Conservation, vol. 7, no. 2, pp. 73-84, 2003.

[36] F. G. Neumann, "Beetle communities in eucalypt and pine forests in North-Eastern Victoria," Australian Forest Research, vol. 9, pp. 277-293, 1979.

[37] J. H. Brown, S. K. M. Ernest, J. M. Parody, and J. P. Haskell, "Regulation of diversity: maintenance of species richness in changing environments," Oecologia, vol. 126, no. 3, pp. 321332, 2001.

[38] L. F. Rodriguez, "Can invasive species facilitate native species? Evidence of how, when, and why these impacts occur," Biological Invasions, vol. 8, pp. 927-939, 2006.

[39] C. B. Anderson and A. D. Rosemond, "Ecosystem engineering by invasive exotic beavers reduces in-stream diversity and enhances ecosystem function in Cape Horn, Chile," Oecologia, vol. 154, no. 1, pp. 141-153, 2007. 

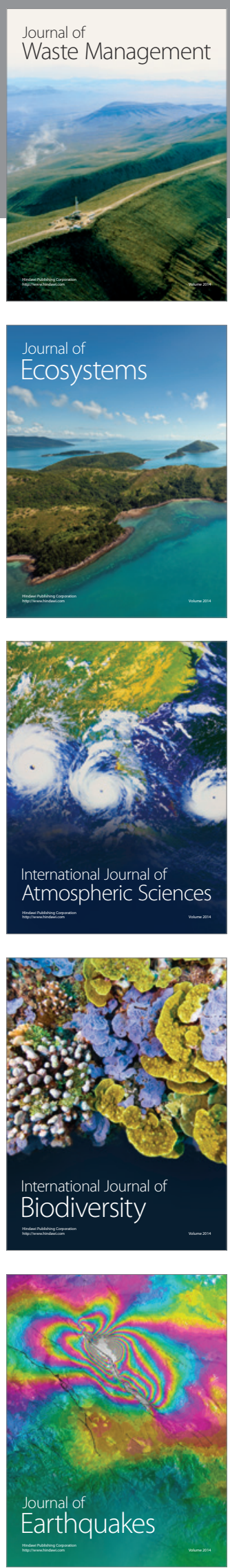
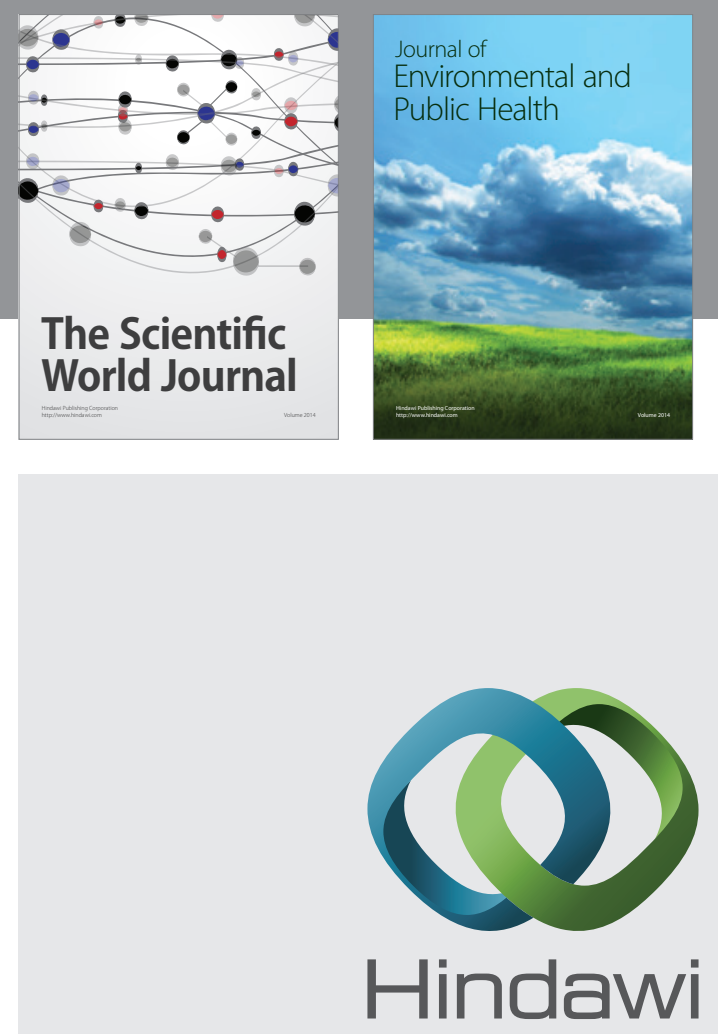

Submit your manuscripts at

http://www.hindawi.com
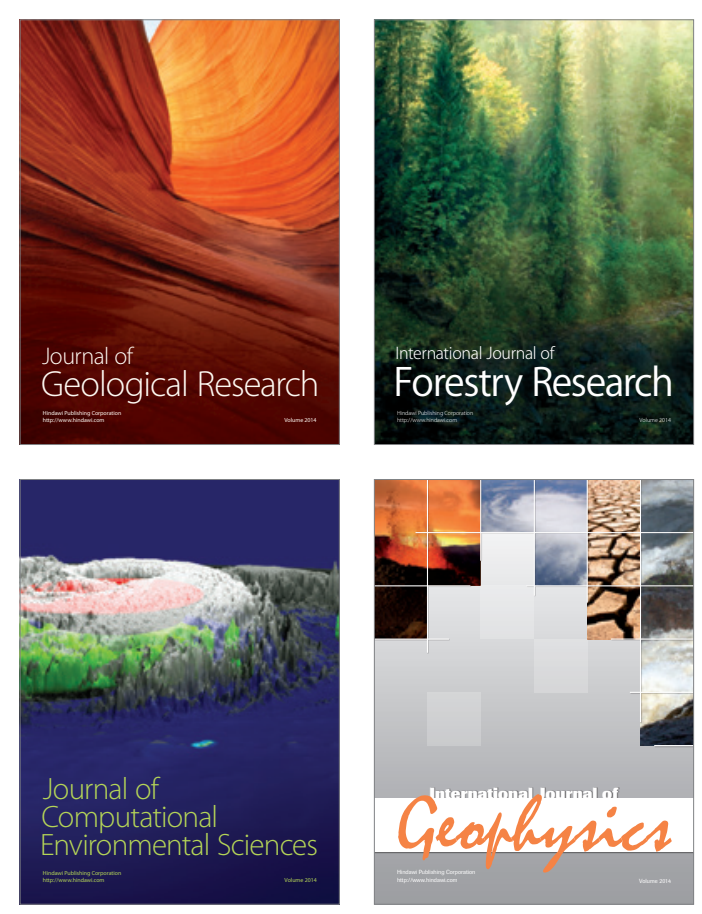
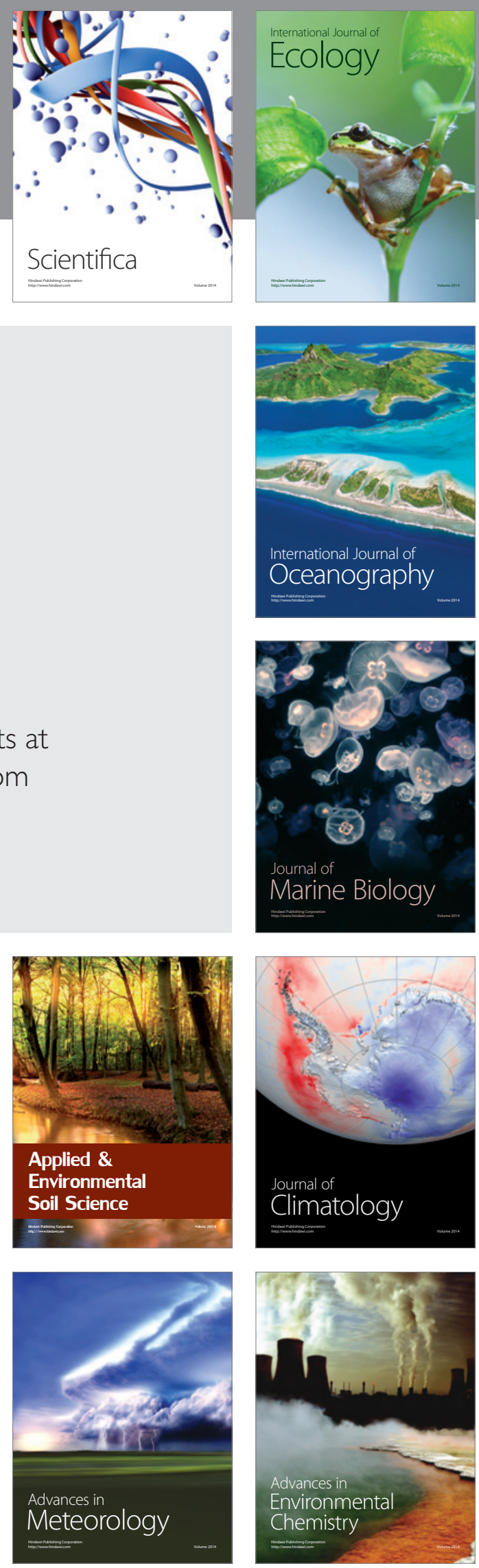